Eye hospitals

\title{
The origin of eye hospitals
}

\section{J Marmion}

\section{Visual recovery in the early 19th century after surgery was no mirage - the benefit was a reality and was sustained}

$\mathrm{T}$ he word "eye" has its origin in Anglo-Saxon, probably from the Baltic languages, with the Fresian "oie" the closest precursor. In middle English it is variously spelt as ighe, eghe, eighe, and eie. It is not surprising that there is a town of Eye in Suffolk, and that eye hospitals are an AngloSaxon phenomenon. Their origin in the early part of the 19th century had been preceded by the recognition of the surgeon oculist as a separate entity on the 18th century medical register. After the inception of eye hospitals ophthalmology was accepted as an individual specialty.

The earliest blind asylums in Europe coincided with the crusades, in Germany at Meiningen (1173) and in France the Quinze Vingts (1266). The latter was specifically founded to treat crusaders "afflicted by the burning plains of Egypt and Syria."

Blind asylums in Dublin (1781), Liverpool (1791), Edinburgh (1793), and Bristol (1799) all preceded the establishment of eye hospitals while, in London, the Blind Asylum at St George's in the Fields, Southwark, was contemporaneous with the Royal London Hospital for Diseases of the Eye and Ear, later known as Moorfields Eye Hospital (1805).

\section{HOW PREVALENT WAS TRACHOMA IN THESE HOSPITALS?}

The prolonged battle of Aboukir in Egypt in 1801 was accompanied on both sides by a severe epidemic during the summer months and, coinciding with scurvy, of a condition referred to as the "Egyptian ophthalmia." This persisted among the forces for some years, it was finally declared over by the inspector general of the army Dr Franklin in 1805. ${ }^{1}$ Fifteen out of the 40 regiments involved at Aboukir came from Scotland, Ireland, and Wales. Both Edinburgh and Dublin had eye hospitals by 1811 and 1814, respectively. Dublin had the old Hospice of the Knights of St John at Kilmainham dedicated to the treatment of the military, where returned soldiers suffering from the ophthalmia received treatment. In
London there was the hospital at Greenwich and the Royal Infirmary for Diseases of the Eye in Cork Street, which dealt with the afflicted soldiers and sailors. A special unit was established in 1805 at Selsea in Sussex for the treatment of army personnel with serious ocular problems among which cataract was prominent. $^{2}$ Sir William Wilde, ${ }^{3}$ in his historical review of epidemics of ophthalmia, records major outbreaks of the disease in the 18th century. He does not record an epidemic of Egyptian ophthalmia in the general population but mentions two civilian outbreaks between 1801 and 1805-one in London the other later in Leeds. Wilde also makes reference to an outbreak of influenza in Ireland in 1803, which was associated with ophthalmia; he says the local population ascribed the origin of ophthalmia to the military. Davidson $^{4}$ ignores Wilde's history of epidemics of ophthalmia and the evidence from provincial eye hospitals.

The census report for England in 1821 makes no mention of ophthalmia. Among the early provincial eye hospitals in their first annual reports both Exeter and Bristol refer to the treatment of soldiers with Egyptian ophthalmia but not the general population. Exeter, Bristol, Bath, Manchester, Edinburgh, Shrewsbury, and Plymouth all petitioned support for relief of blindness among the poor without specifying any disease. It is significant that blind asylums were established long before the return of military personnel from Egypt.

\section{THE RELEVANCE OF SMALLPOX}

The reports of the Bristol Eye Dispensary ${ }^{5}$ between 1820 and 1832 provide details of the annual new cases of ocular smallpox. JB Estlin, the surgeon in charge, carried forward an aggressive practice of vaccination, often harvesting lymph from cows himself to be certain of its quality, all his patients attending had to submit to vaccination unless they had recovered from the disease. MacKenzie, ${ }^{6}$ in his textbook in 1830 , states that smallpox was a major cause of blindness and the official census of $1861^{7}$ records smallpox as the major cause of blindness and commends the establishment of eye hospitals for the work undertaken to relieve blindness and the advancement of the specialty. MacKenzie devoted an earlier section of his book to an ophthalmia which is referred to as the Egyptian, the major part of this section he quotes from military surgeons.

\section{CATARACT}

Reports from provincial eye hospitals gave clear evidence of an increasing number of operations for ectropium, artificial pupil and cataract, their acceptance by patients, and provide clear evidence of the benefit and failuresthe latter were few. Detailed examination of the reports of the hospitals at Exeter, Bath, Plymouth, Manchester, and both the Bristol Eye Hospital (1810) and the Bristol Eye Dispensary (1812) shows clearly that the remedial form of blindness which attracted most attention was cataract. Brisseau, ${ }^{8}$ between 1704 and 1710 using couching instruments taken from an itinerant English oculist, through a number of experiments demonstrated as untenable the Galenic concept that the seat of vision was in the lens. He also demonstrated that cataract could be caused by cannon blast and that soldiers could be returned to duty following successful treatment. The next major advance was a more anterior approach to cataract removal by Daviel (1752). ${ }^{9}$ This received general acceptance though old practices were slow to change. Reports such as that by Sharp $(1753)^{10}$ to the Royal Society and the monograph by Borthwick $(1794)^{11}$ affirm the widespread interest of these developments among practising surgeons.

Cataract and its ensuing blindness became a remedial problem. It is not surprising that a significant amount of military cataract was dealt with at Greenwich, Cork Street, Kilmainham, and Selsea. There was controversy between Vetch and Adams over surgical procedures and their results, which required the intervention of the Prince Regent. ${ }^{12}$ Saunders's work coupled with the reports of the provincial eye hospitals indicate a higher incidence of cataract among children than would be anticipated at present. Prescription of spectacles for aphakic correction had been established in the 18th century. All of these advances, in conjunction with predictable surgical outcome, laid the basis for blind asylums to develop into blind schools following the establishment of eye hospitals The number of cases seen and the range of disease at any centre would have presented difficulties with accommodation in the general hospitals from which most of 
the founding surgeons originated. The position in London differed socially as Saunders, Farre, and Battley discovered when founding Moorfields.

Eye hospitals had firmly established their base in society by the time of the 1861 census report. They were not without their critics. ${ }^{13}$ The presidents of the royal colleges supported by an editorial, and later an ophthalmologist, ${ }^{14}$ maintained that no part of the body should be dealt with in isolation. While the president of the Royal Society, Sir Benjamin Brodie, signed this letter, he independently suggested that eye hospitals should continue their separate existence. This many have continued to do, with distinction, over nearly 200 years. Their success, as judged by relief of blindness, lay with the acceptance of operations to form an artificial pupil and correction of ectropion, but more so with the advances in cataract surgery.

Br J Ophthalmol 2005;89:1396-1397.

doi: 10.1136/bjo.2005.078170

Correspondence to: V J Marmion, Emeritus consultant, Bristol Eye Hospital, Lower Maudlin Street, Bristol BS1 2LX, UK; vincent@vjm.

demon.co.uk

\section{REFERENCES}

1 Farrell C. Observations on ophthalmia and its consequences. London: John Murray and Edinburgh, Blackwood, 1811:2.

2 Cantlie Lt Gen Neil. Ophthalmia in a history of the army medical department. Edinburgh: Churchill Livingstone, 1974:275.

3 Wilde Sir WW. Report of the census of Ireland 1861;5:49-55.

4 Davidson L. 'Identities ascertained.' British ophthalmology in the first half of the nineteenth century. Social History of Medicine 1996;9:313-33

5 Richard Smith Diaries, Vol VIII and reports of the Bristol Eye Dispensary, Bristol City Archives.

6 Mackenzie Sir W. A practical treatise on diseases of the eye. London: Longman Rees Orme Brown \& Green, 1830, 337-60, 402-5.

7 Census of England. Vol 3 Report of the Registrar General 1861:43.

8 Brisseau M. Traite du Cataract et du Glaucome Laurent d'Houry, Paris, 1709.

9 Daviel J. Memoires de l' Academie Royale de Churgurie 1753;ii:337.

10 Sharp J. A description of a new method of opening the cornea to extract the crystalline humour. Phil Trans Roy Soc 1753;48:161-3, 322-31.

11 Borthwick G. A treatise on the extraction of the crystalline lens. Edinburgh: Charles Elliott, 1775

12 Vetch J. A letter to the Right Honorable Lord Viscount Palmerston Secretary of State For War \&c \&c on the Subject of the Ophthalmic Institution for the Chelsea Pensioners. Burgess Hill, London, 1819:1-29.

13 Editorial and letters on special hospitals. Lancet 1860;88:97

14 Laurence JZ. Editorial. Ophthalmic Rev 1866;18:319-30. 